\title{
Seismic Response Characteristics of Stabilizing Pile Based on Elastic-Plastic Analysis
}

\author{
Honglue Qu (D), ${ }^{1}$ Ying Liu, ${ }^{1}$ Hao Luo, ${ }^{1}$ Huanguo Hu $\left(\mathbb{D},{ }^{2}\right.$ and Qindi $\mathrm{Hu}^{1}$ \\ ${ }^{1}$ School of Geoscience and Technology, Southwest Petroleum University, Chengdu 610500, China \\ ${ }^{2}$ China Chemical Geology and Mine Bureau (Henan Geological Bureau), Zhengzhou 450011, China \\ Correspondence should be addressed to Honglue Qu; geoqhl@126.com
}

Received 27 January 2018; Revised 28 April 2018; Accepted 13 May 2018; Published 25 June 2018

Academic Editor: Yuri S. Karinski

Copyright (c) 2018 Honglue Qu et al. This is an open access article distributed under the Creative Commons Attribution License, which permits unrestricted use, distribution, and reproduction in any medium, provided the original work is properly cited.

\begin{abstract}
Stabilizing pile is widely used in the landslide controlling projects and shows excellent seismic performance under the action of earthquake. Therefore, in order to improve seismic design theory, it is of importance to study the seismic response characteristics of stabilizing pile based on elastic-plastic analysis. In view of this, elastic-plastic constitutive model was established to deduce the plastic zone of stabilizing pile. Based on elastic-plastic analysis, the seismic response characteristics and the influence of different section sizes, material strengths, and peak ground motion acceleration (PGA) were analyzed by ANSYS 3D. Resultantly, the elastic-plastic fourth-order tensor $C_{i j k l}^{e p}$ was deduced, which can be used to calculate plastic strain of stabilizing pile under loading. Compared with Chinese code, the material of stabilizing pile working with elastic-plastic state will be decreased under the same section size and the same property. Furthermore, stabilizing pile is in the elastic stage at the beginning under the action of earthquake. With the increase of ground motion time, the section starts to exhibit elastic-plastic state and then the plastic zone expands gradually. Finally, the plastic zone runs through the whole section, resulting in the performance loss of the pile. In addition, under the different design parameters, pile shows different seismic response characteristics; namely, changing these parameters reasonably can improve the seismic design.
\end{abstract}

\section{Introduction}

Stabilizing pile, as a flexible retaining structure, has advantages of convenient construction, flexible arrangement, and strong stabilizing ability, which is widely used in the treatment of geological hazards in recent years [1-3] and also shows excellent seismic performance in Wenchuan earthquake [4]. Therefore, in order to provide a theoretical basis for optimizing seismic design system, it is necessary to study the seismic response characteristics of stabilizing pile based on elastic-plastic analysis.

Nowadays, many researches about stabilizing pile have been carried out [5-8]. On the one hand, many scholars put forward the corresponding calculation formula in view of pile spacing [9], pile length [10], embedded depth [11], and so on to optimize the structure design, which provided theory basis for the engineering practical application of stabilizing pile [12]. On the other hand, as an important measure to control landslides, the seismic response characteristics of slope soil and pile-soil interaction were also research topics in geotechnical engineering. For example, Luan et al. [13] established a consolidated soil-pile model to analyze pile side friction force and seismic response of soil by considering the pile-soil interaction. Fard and Rasoolan [14] investigated soilpile interaction using the numerical method and provided greater familiarity with force distribution in deformation mechanisms in the soil as well as soil-pile interaction.

The above researches mainly focus on the structure design, the pile-soil interaction, and the seismic response characteristics of reinforced soil. However, the research on elastic-plastic analysis of stabilizing pile under the action of earthquake is still rare [15]. In view of this, elastic-plastic constitutive model was established to deduce the plastic zone of stabilizing pile. Based on elastic-plastic analysis, the seismic response characteristics of stabilizing pile and the influence of different design parameters were analyzed, such 
as section size, material strength, and PGA. The results of numerical analysis can provide a basis for the optimization of stabilizing pile seismic design system [16].

\section{Elastic-Plastic Theory of Stabilizing Pile}

2.1. The Establishment of Constitutive Model. During the process of the structural design with elastic theory, the stabilizing pile fails to meet the material damage conditions completely so that the design is conservative and the masonry is wasteful. Therefore, it is necessary to establish the elasticplastic constitutive model, which is advantageous to make full use of materials and maximize their performance.

The elastic constitutive relationship is not applicable when the stress state of stabilizing pile in particular point meets yield condition and goes into plastic deformation stage. Therefore, it is necessary to establish stress-strain relationship for describing the elastic-plastic behavior of that point.

The stress state can be simplified down to plane stress state because the length is much greater than the width of stabilizing pile. On account of von Mises yield criterion, stabilizing pile can be viewed as isotropic material in the elastic stage and it will be viewed as isotropic hardening material in the plastic stage. On the basis, the elastic-plastic stress and strain can be calculated according to the external loading of stabilizing pile, and the size of plastic zone can be calculated in the case of plastic hinge. Finally, a numerical simulation with ANSYS was used to verify the correctness of elastic-plastic constitutive model.

From the elastic-plastic theory, it can be seen that elastic increment plus plastic increment is strain increment [17], that is,

$$
d \varepsilon_{i j}=d \varepsilon_{i j}^{e}+d \varepsilon_{i j}^{p}
$$

In $(1), \varepsilon_{i j}, \varepsilon_{i j}^{e}$, and $\varepsilon_{i j}^{p}$ are second-order strain tensor, second-order elastic strain tensor, and second-order plastic strain tensor, respectively. The relationship between elastic strain increment and stress increment is shown in (2), where $\sigma_{i j}$ is second-order stress tensor and $C_{i j k l}$ is fourth-order elastic tensor. Additionally, the plastic strain increment can be expressed by plastic potential function and flow rule equation, as shown in (3), where $\lambda$ is positive scalar.

$$
\begin{aligned}
& d \sigma_{i j}=C_{i j k l} d \varepsilon_{k l}^{e} \\
& d \varepsilon_{i j}^{p}=d \lambda \frac{\partial g}{\partial \sigma_{i j}}
\end{aligned}
$$

Combining (1), (2), and (3), (4) can be obtained.

$$
d \sigma_{i j}=C_{i j k l}\left(d \varepsilon_{k l}-d \lambda \frac{\partial g}{\partial \sigma_{i j}}\right)
$$

2.1.1. Initial Yield. Based on the relationship between stress increment and strain increment, $f$ equals $g$ when the associated flow rule is adopted. Taking von Mises criterion as yield condition, the initial yield condition is given in (5), where $K(k)$ is hardening function, $k$ is hardening parameter, and

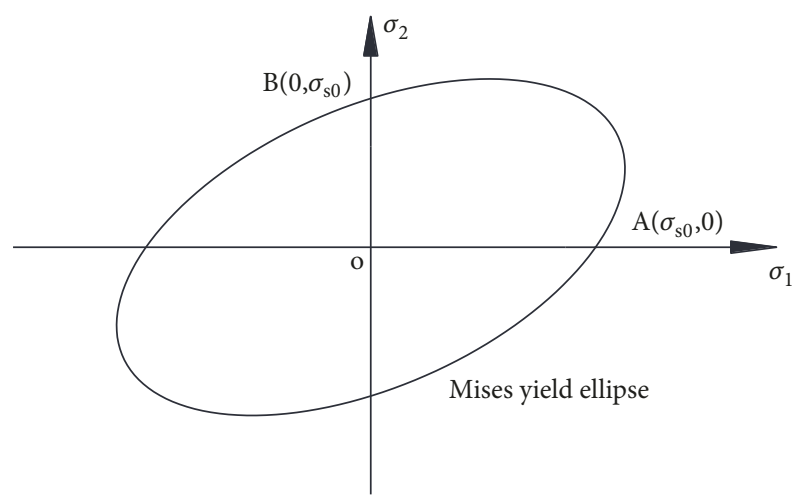

FIGURE 1: The von Mises yield criterion in $\sigma_{2}-\sigma_{1}$ coordinate plane.

$J_{2}$ is the second invariant of stress deviator. In view of this, subsequent yield function for isotropic hardening is shown in (6) and (7), where $s_{i j}$ is second-order stress deviator, $\sigma_{e}$ is elastic stress, $\bar{\varepsilon}^{p}$ is equivalent plastic strain, and $E_{e}, E_{p}$, and $E_{t}$ are elastic modulus, plastic modulus, and tangent modulus, respectively, which satisfied (8).

$$
\begin{aligned}
f\left(\sigma_{i j}, k\right) & =J_{2}-K(k)=0 \\
\frac{1}{2} s_{i j} s_{i j}-\frac{1}{3} \sigma_{\varepsilon}^{2}\left(\bar{\varepsilon}^{p}\right) & =0 \\
\text { or } J_{2}-\frac{1}{3} \sigma_{\varepsilon}^{2}\left(\bar{\varepsilon}^{p}\right) & =0 \\
d \sigma & =E_{e} d \varepsilon^{e} \\
d \sigma & =E_{p} d \varepsilon^{p} \\
d \sigma & =E_{t} d \varepsilon \\
\frac{1}{E_{e}}+\frac{1}{E_{p}} & =\frac{1}{E_{t}}
\end{aligned}
$$

In von Mises yield criterion, the yield surface is cylindrical surface in principal stress space with the average principal stress axes. The intersecting line among yield plane, $\pi$ plane, and flat plane is a circle with the radius of $\sqrt{2} k$, while it is an ellipse in $\sigma_{2}-\sigma_{1}$ coordinate plane, as shown in Figure 1.

In addition, the equation of the ellipse is shown in (9), where $\sigma_{1}, \sigma_{2}$, and $\sigma_{s 0}$ are first main stress, second main stress, and initial yield stress, respectively. Therefore, the yield function at the time of initial yield is given in

$$
\begin{aligned}
\sigma_{1}^{2}+\sigma_{2}^{2}-\sigma_{1} \sigma_{2} & =\sigma_{s 0}^{2} \\
f^{0}\left(\sigma_{i j}\right) & =\frac{1}{2} \frac{1}{2} s_{i j} s_{i j}-\frac{1}{3} \sigma_{s 0}^{2}=0
\end{aligned}
$$

2.1.2. Subsequent Yield under Loading. When the elasticplastic deformation occurs, the boundary of elastic zone is constantly changing, and plastic state will inevitably follow the change. The yield functions are shown in (11), so (12) 


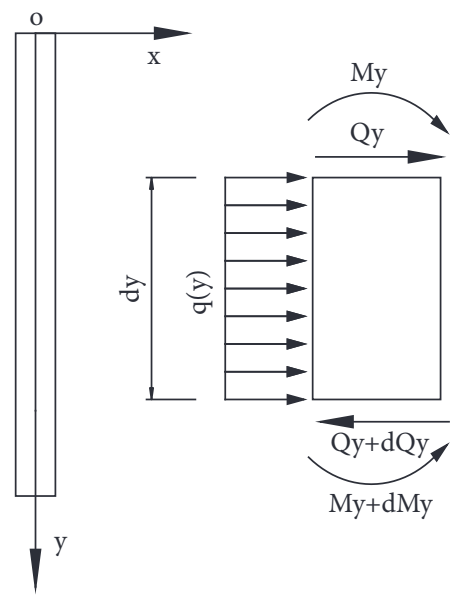

FIGURE 2: Internal force calculation of stabilizing pile.

can be obtained. Combining (4), (10), and (12), elasticplastic tensor of isotropic hardening material under the yield condition can be solved in (13).

$$
\begin{aligned}
& f\left(\sigma_{i j}, \bar{\varepsilon}^{p}\right)=0, \\
& f\left(\sigma_{i j}+d \sigma_{i j}, \bar{\varepsilon}^{p}+d \bar{\varepsilon}^{p}\right)=0 \\
& \frac{\partial f}{\partial \sigma_{i j}} d \sigma_{i j}+\frac{\partial f}{\partial \bar{\varepsilon}^{p}}=0 \\
& C_{i j k l}^{e p}=C_{i j k l}-\frac{s_{i j} s_{k l}}{\left(1 / 9 G^{2}\right)\left(E_{p}+3 G\right) \sigma_{e}^{2}}
\end{aligned}
$$

Therefore, the elastic-plastic constitutive tensor of stabilizing pile with isotropic hardening on the plane is shown in (14), where $\mu$ is Lame coefficient, $G$ is shear modulus, $C_{i j k l}^{e p}$ is fourth-order elastic-plastic tensor, and $s_{x}$ and $s_{y}$ are stress deviator along the $x$ direction and $y$ direction, respectively.

$$
\begin{aligned}
C_{i j k l}^{e p} & =\left[\begin{array}{ccc}
\mu+G & \mu & 0 \\
\mu & \mu+G & 0 \\
0 & 0 & G
\end{array}\right] \\
& -\frac{1}{\left(1 / 9 G^{2}\right)\left(E_{p}+3 G\right) \sigma_{e}^{2}}\left[\begin{array}{ccc}
s_{x} s_{x} & s_{x} s_{y} & s_{x} \tau_{x y} \\
s_{y} s_{x} & s_{y} s_{y} & s_{y} \tau_{x y} \\
\tau_{y x} s_{x} & \tau_{y x} s_{y} & \tau_{y x} \tau_{x y}
\end{array}\right]
\end{aligned}
$$

2.2. The Determination of Plastic Zone. Slip mass behind cantilever section of stabilizing pile is simplified as known external force. In order to facilitate the mechanical analysis for embedded segment, stress analysis coordinate system of stabilizing pile is established when the top of embedded segment is taken as the origin [18], as shown in Figure 2.

Based on the balance of microsection, force relationship is given in (15), where $Q_{y}$ is the shear force, $q(y)$ is the loading in the $y$ direction, and $M_{y}$ is bending moment. Furthermore, (16) and (17) can be obtained based on the principle of material mechanics, where $f(y)$ is horizontal displacement along $y$-axis, $E$ is elastic modulus, and $I$ is cross-sectional moment of inertia of pile. Subgrade reaction of pile meets the relationship $q(y)=C f(y)$. Therefore, subgrade reaction beard by cross-section of pile meets the relationship of (18), where $C$ is foundation coefficient, $B_{p}$ is calculative width of pile. In view of the above, and (19) can be obtained.

$$
\begin{aligned}
\frac{d Q_{y}}{d y} & =q(y) \frac{d M_{y}}{d y}=Q_{y} \\
x(y) & =f(y), \\
\varphi(y) & =\frac{d x_{y}}{d y} \\
\frac{M_{y}}{\mathrm{EI}} & =-\frac{d^{2} f(y)}{d y^{2}}, \\
\frac{Q_{y}}{\mathrm{EI}} & =-\frac{d^{3} f(y)}{d y^{3}} \\
q(y) & =C B_{p} f(y) \\
\mathrm{EI} \frac{d^{4} f(y)}{d y^{4}}+C B_{p} f(y) & =0
\end{aligned}
$$

The stress of stabilizing pile at any position is shown in Figure 3 , and the normal stress and shear stress can be solved by (20) and (21), where $h$ is cross-sectional height, $b$ is crosssectional width of pile, and $I_{z}$ is inertia moment with $z$ as the symmetry axis. In addition, principal stress in the plane and stress deviator along the $x$ and $y$ direction can be obtained, which are described in (22) and (23).

$$
\begin{aligned}
\sigma_{x} & =\frac{M_{y} x}{I_{z}}, \\
\tau_{x y} & =\frac{Q_{y} S_{z}^{*}}{I_{z} b} \\
S_{z}^{*} & =\int_{x}^{h / 2} x b d x=\frac{b}{2}\left(\frac{h^{2}}{4}-x^{2}\right) \\
\sigma_{1} & =\frac{M_{y} x}{2 I_{z}}+\sqrt{\frac{M_{y}^{2} x^{2}}{4 I_{z}^{2}}+\frac{Q_{y}^{2} S_{z}^{* 2}}{I_{z}^{2} b^{2}},} \\
\sigma_{2} & =\frac{M_{y} x}{2 I_{z}}-\sqrt{\frac{M_{y}^{2} x^{2}}{4 I_{z}^{2}}+\frac{Q_{y}^{2} S_{z}^{* 2}}{I_{z}^{2} b^{2}}} \\
s_{x} & =\frac{2 M_{y} x}{3 I_{z}}, \\
s_{y} & =-\frac{M_{y} x}{3 I_{z}}
\end{aligned}
$$




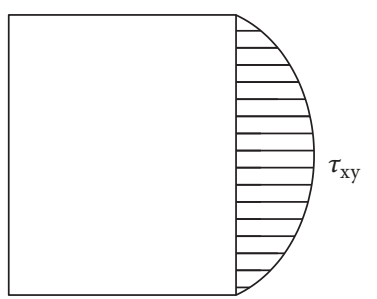

(a)

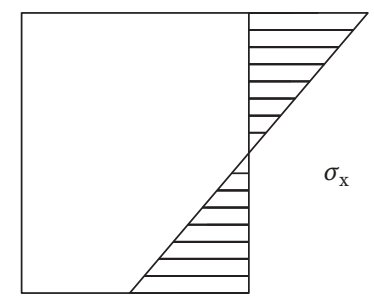

(b)

FIGURE 3: Internal force of pile. (a) Shear stress; (b) normal stress.
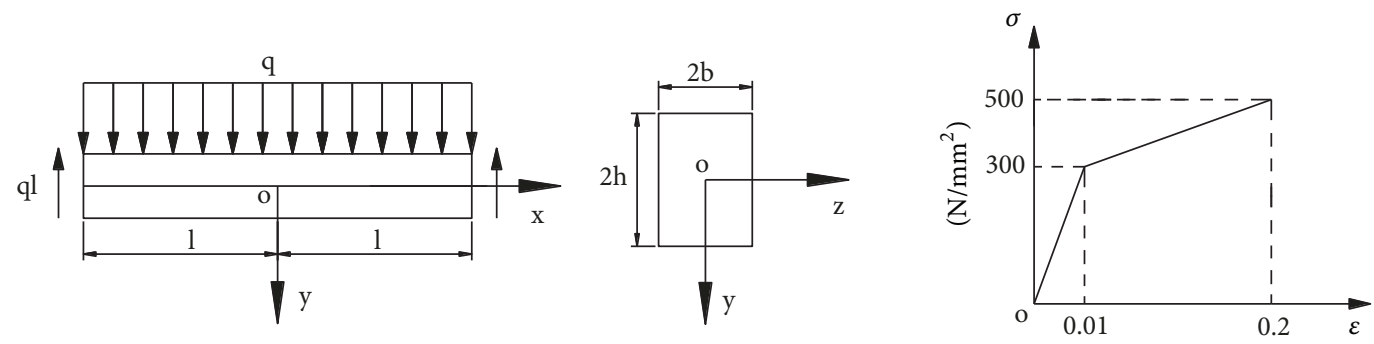

FIGURE 4: The numerical model and material property in ANSYS.

When the initial yield happens, the yield function equals 0 , as shown in (24). Furthermore, elastic and plastic ultimate loading can be given by (25). With the increase of loading, plastic zone begins to extend from the position with the maximum stress. Supposing that the $x$-coordinate of the intersection between plastic zone and elastic zone on $y$ crosssection is $s(y)$, these points on the cross-section are still in elastic state when the value range of $x$ axis is $-s(y) \leq x \leq s(y)$ and the value of $\sigma_{x}$ is a linear distribution, as shown in (26), where $\sigma_{x}$ is yield stress.

$$
\begin{aligned}
f^{0}\left(\sigma_{i j}\right) & =\frac{2 M_{y}^{2} x^{2}}{I_{z}^{2}}+\frac{6 Q_{y}^{2} S_{z}^{* 2}}{I_{z}^{2} b^{2}}-\frac{\sigma_{s 0}^{2}}{3}=0 \\
M_{y} & =\int_{-h}^{h} x\left(\sigma_{x} 2 b d x\right) \\
\sigma_{x} & =\frac{x}{s(y)} \sigma_{s} \quad-s(y) \leq x \leq s(y)
\end{aligned}
$$

Therefore, in the plastic zone, the stress relationships are given in (27) and (28) and the function of the plastic zone $s(y)$ can be obtained, as shown in (29).

$$
\begin{aligned}
\sigma_{x} & =\sigma_{s} \quad s(y) \leq x \leq h \\
\sigma_{x} & =-\sigma_{s} \quad-h \leq x \leq-s(y) \\
s(y) & = \pm \sqrt{3 h^{2}-\frac{3 M_{y}}{2 \sigma_{s} b}}
\end{aligned}
$$

2.3. Verification of Constitutive Model and Elastic-Plastic Zone. The elastic-plastic zone of simply supported beam under uniform distributed loading was analyzed by ANSYS, and then the correctness of elastic-plastic constitutive relationship and plastic zone of isotropic hardening material satisfying von Mises yield condition was verified according to the results of numerical simulation. The material is supposed to be elastic-plastic and bilinear isotropic hardening material, which meets von Mises yield criterion. The sectional dimension was taken as $b \times h=1 \mathrm{~m} \times 2 \mathrm{~m}$ and the length was $5 \mathrm{~m}$, as shown in Figure 4. In addition, the initial yield was assumed to happen when the strain was 0.01 and began to damage when the strain reached 0.2 . In the process of loading, the material property was assumed to meet the requirement of linear hardening. Uniform linear loading was applied at the top of the pile, which increases from 0 to $30 \times 10^{6} \mathrm{~N} / \mathrm{m}$.

2.3.1. Validation of Elastic-Plastic Limit State. According to the stress analysis, it is known that the stress of cross-section in the middle of beam is the maximum. Therefore, elasticplastic limited state of the cross-section should be considered firstly. When $s(0)=h$, through (29), the bending moment of cross-section reaches yield stage firstly and the elastic limited bending moment $M_{e}$ can be obtained. When the crosssection reaches the yield stage absolutely, the corresponding bending moment is named plastic limit bending moment $M_{p}$. At this time, $s(0)=0,(30)$ and (31) can be obtained.

$$
\begin{aligned}
M_{e} & =\frac{4}{3} \sigma_{s} b h^{2} \\
M_{p} & =2 \sigma_{s} b h^{2} \\
q_{e} & =\frac{8}{3} \sigma_{s} b\left(\frac{h}{l}\right)^{2} \\
q_{p} & =4 \sigma_{s} b\left(\frac{h}{l}\right)^{2}
\end{aligned}
$$

In (30) and (31), $M_{e}$ and $M_{p}$ are elastic limited bending moment and plastic limited bending moment, respectively, 


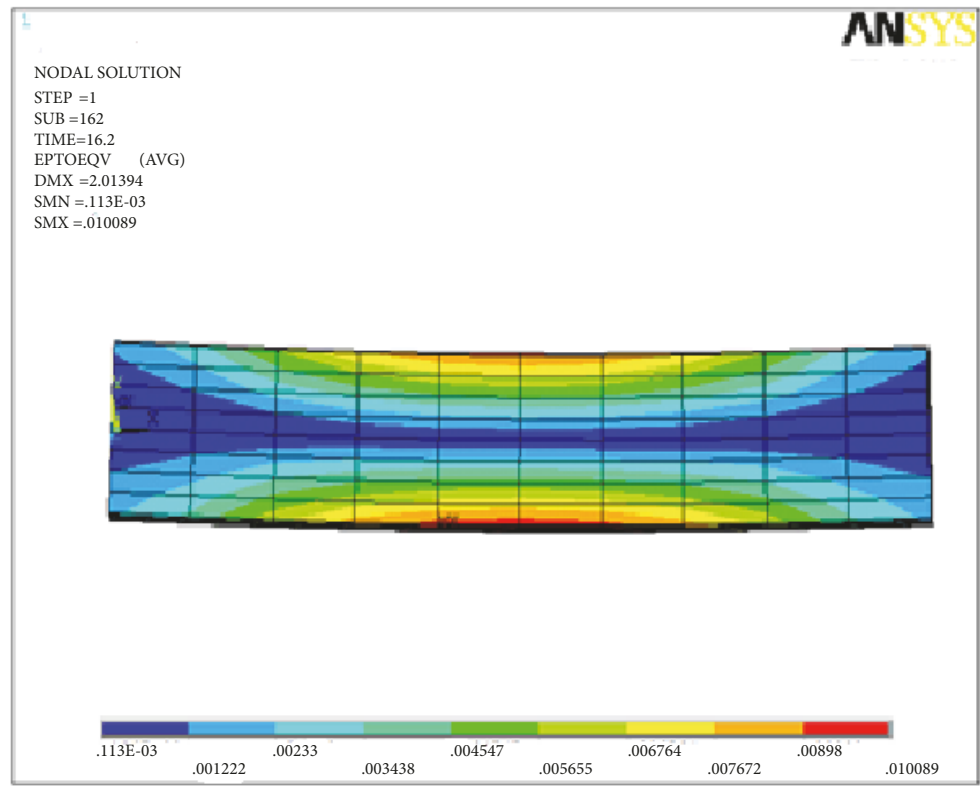

FIGURE 5: Elastic limited state analyzed by ANSYS.

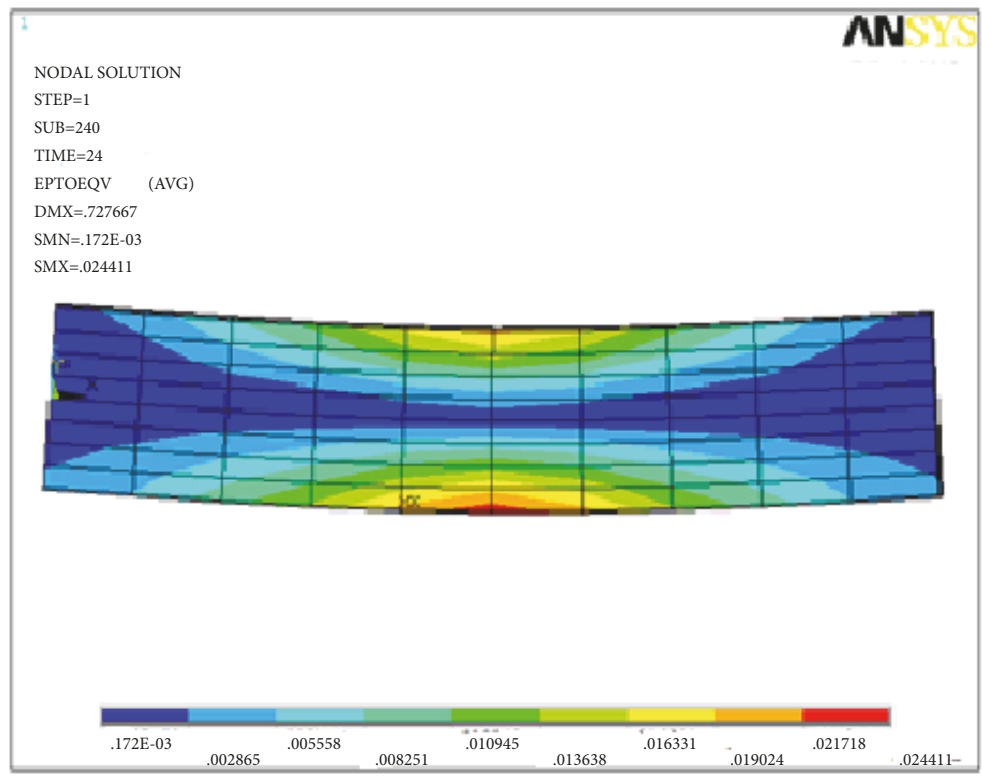

FIGURE 6: Plastic limited state analyzed by ANSYS.

and $q_{e}$ and $q_{p}$ is elastic limited loading and plastic limited loading, respectively.

Through (31), it can be seen that the beam is in the elastic limited state when $q_{e}=16 \times 10^{6} \mathrm{~N} / \mathrm{m}$; namely, the yield of the middle-beam just happens when $q=q_{e}$. At that moment, the strain is $\varepsilon=0.01$, as shown in Figure 5. In addition, the beam is in the plastic limited state when $q_{p}=24 \times$ $10^{6} \mathrm{~N} / \mathrm{m}$ according to the calculation, namely, $q=q_{p}$. At the same time, the cross-section in the middle of beam reaches complete yield state and the plastic hinge is developed in the numerical simulation analysis, which satisfied the results of (31), as shown in Figure 6.

2.3.2. Validation of Plastic Zone. The comparison of equivalent stress and yield strength of the material itself under the external loading can be used as a basis for judging whether the structure shows plastic zone. This means that when the two values are equal at a certain point, the pile reaches the critical point of yielding at that point. Therefore, the range of plastic zone can be obtained according to the position of 


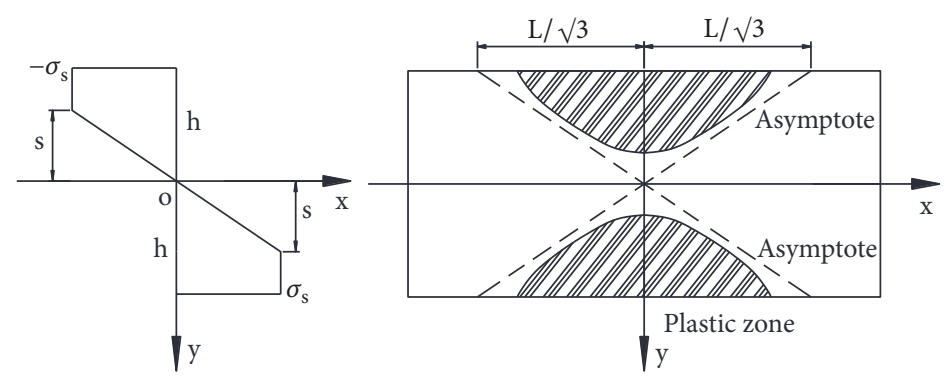

Figure 7: Plastic zone of simply supported beam.

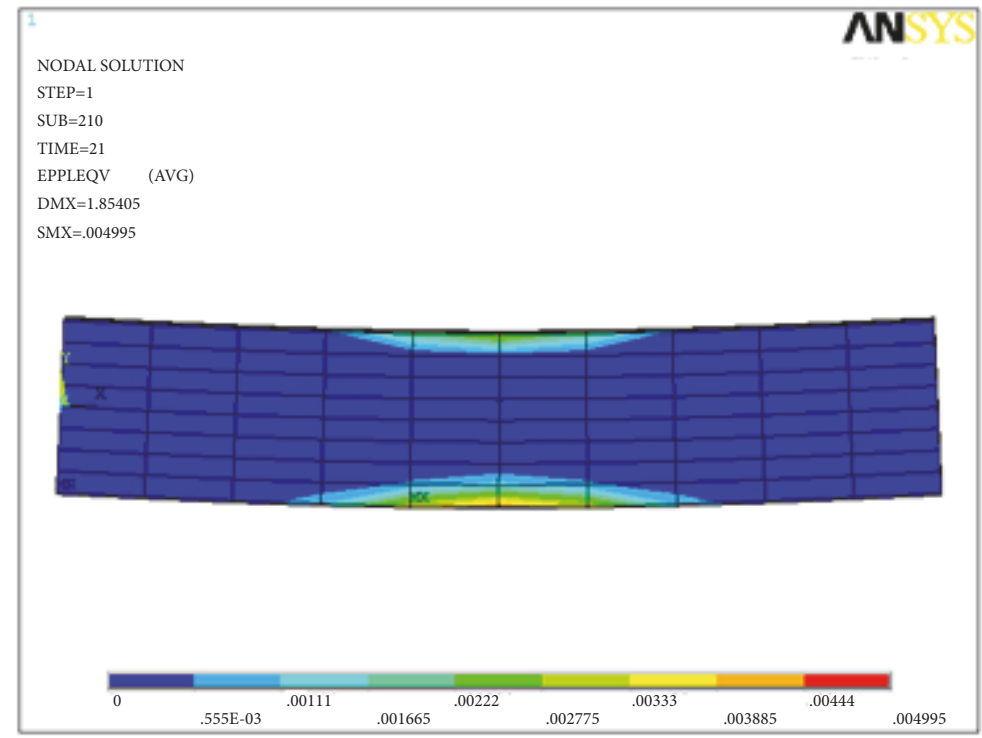

FIGURE 8: The plastic zone analyzed by ANSYS.

the critical point, and the subsequent yield equivalent stress of each part of plastic zone can be obtained on the basis of plastic hardening criterion.

Through (29), the plastic zone of simply supported beam can be obtained, as shown in Figure 7.

When $q=21 \times 10^{6} \mathrm{~N} / \mathrm{m}$, plastic zone happened in the interval $[-L / \sqrt{3}, L / \sqrt{3}]$, which is consistent with the results analyzed of numerical simulation, as shown in Figure 8.

2.3.3. Validation of Plastic Hardening under Loading. When $q=21 \times 10^{6} \mathrm{~N} / \mathrm{m}$, there is $q_{e}<q<q_{p}$. At this moment, the middle of beam is in elastic-plastic state. Putting the value above into (8), (14), (23), and (29), then the value of total strain can be obtained, namely $\varepsilon_{i j}=\varepsilon_{i j}^{e}+\varepsilon_{i j}^{p}=0.0102+$ $0.0055=0.01577$, which is also consistent with the result of numerical simulation, as shown in Figure 9.

The numerical simulation was used to analyze the simply supported beam subjected to uniformly distributed loading to verify the correctness of the elastic-plastic constitutive model and plastic zone mentioned above. The results show that the derived plastic zone and plastic strain are consistent with that of numerical simulation; namely, the formulas of elastic-plastic constitutive model and plastic zone proposed in this paper can be applied to the elastic-plastic analysis of isotropic hardening materials which meet the von Mises yield criterion.

However, the design of stabilizing pile is carried out by static method in Chinese code for seismic design of railway [19] and highway engineering [20] at present; namely, the effect of earthquake on the pile is expressed by equivalent loading, and then the internal force and displacement are calculated by static analysis with the equivalent loading, so as to check the seismic bearing capacity and deformation of the pile. Certainly, the static method, as an accepted and frequently used method, can satisfy the requirement of seismic design and has many advantages, such as simply calculation and rich experience. However, the code is mainly for prevention so that the stabilizing pile designed by static method is more abundant than the actual one. According to Figure 4, under the same section size and same property, the ultimate stress of the pile with elastic-plastic analysis is $500 \mathrm{~N} / \mathrm{mm}$ and the pile reaches the state of complete yielding at this time, while the stress is only $300 \mathrm{~N} / \mathrm{mm}$ with static method, as the code assumes that the pile only exists in elastic state under the action of earthquake. If the pile has to bear 


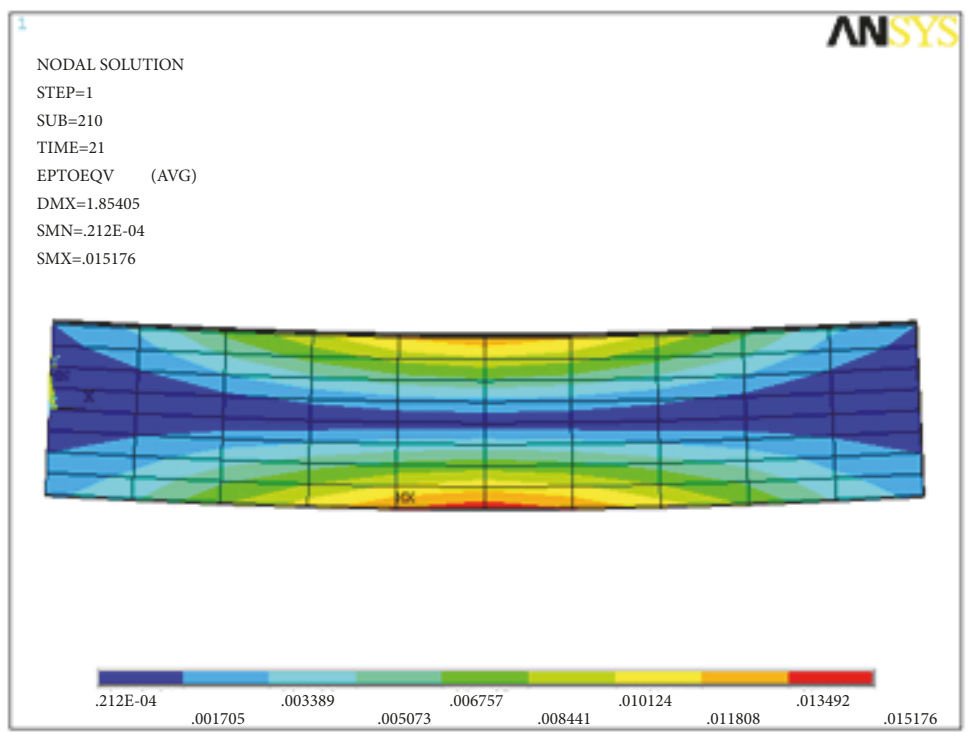

FIGURE 9: Elastic strain and plastic strain analyzed by ANSYS.

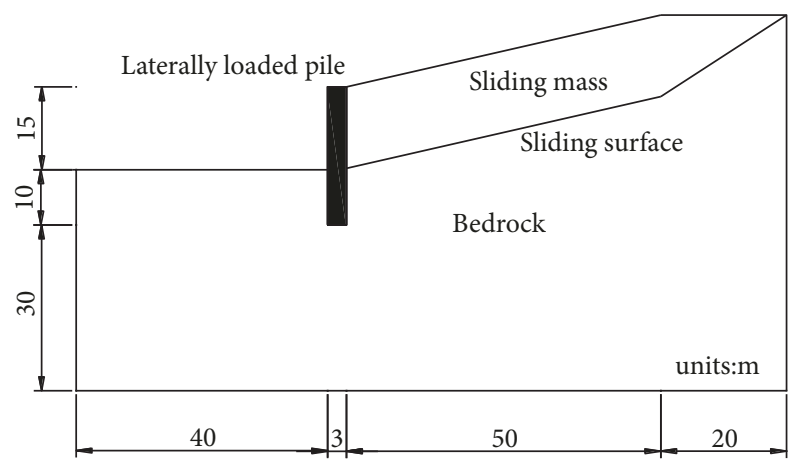

(a)

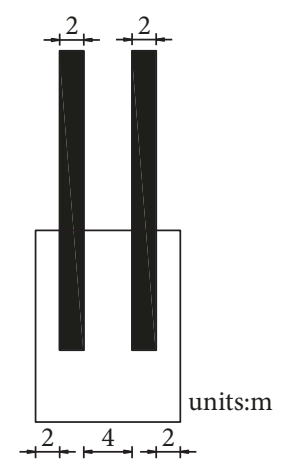

(b)

Figure 10: Structural design and landslide characteristics of the model. (a) The landslide characteristics; (b) the design parameters of stabilizing pile.

the ultimate stress of $500 \mathrm{~N} / \mathrm{mm}$, it is necessary to increase the section size, which will undoubtedly increase material consumption and cause waste. Therefore, the establishment of elastic-plastic constitutive model is beneficial to make full use of materials and maximize their performance.

\section{Model Design}

3.1. Model and Parameters of Numerical Simulation. A model was established by ANASYS 3D to analyze the seismic response characteristics of stabilizing pile and the piles were made of C20 reinforced concrete, as shown in Figure 10. In addition, the length of the pile was $25 \mathrm{~m}$, where the embedded depth was $10 \mathrm{~m}$. The section size of a pile was $2 \mathrm{~m} \times 3 \mathrm{~m}$ $(B \times H)$, and the spacing of pile centers $L$ was $6 \mathrm{~m}$. The calculated model parameters are shown in Table 1.

When the numerical calculation was performed with ANSYS and LS-DYNA, the first was implicit static analysis by ANSYS, and then the results of static analysis would be input into LS-DYNA as the initial conditions. Finally, the Wenchuan Wolong seismic wave was input for explicit dynamic analysis. In the simulation, block element was chosen to simulate slide mass, bedrock, and stabilizing pile, where SOLID 185 block element is in implicit analysis with ANSYS and SOLID 164 block element is in explicit analysis with LS-DYNA. In addition, the D-P constitutive model was adopted in the numerical model. The no reflection boundary conditions and Rayleigh damping were selected for dynamic calculation. The mesh generation is shown in Figure 11. Furthermore, the monitoring points were arranged behind the piles which were prone to plastic yield with the vertical spacing of $1 \mathrm{~m}$ from the bottom to the top of a pile.

3.2. Input of Seismic Wave. Wenchuan wolong seismic wave, with time $0 \sim 15 \mathrm{~s}$, was input after baseline correction and the direction was horizontal direction which was perpendicular 
TABLE 1: The calculation parameters of stabilizing piles.

\begin{tabular}{|c|c|c|c|c|c|c|}
\hline Materials & $\begin{array}{c}\text { Elastic modulus } \\
{[\mathrm{MPa}]} \\
\end{array}$ & Poisson ratio & Cohesion $[\mathrm{kPa}]$ & $\begin{array}{c}\text { Internal friction angle } \\
{\left[{ }^{\circ}\right]}\end{array}$ & $\begin{array}{l}\text { Yield strength } \\
{[\mathrm{MPa}]}\end{array}$ & Density $\left[\mathrm{kg} / \mathrm{m}^{3}\right]$ \\
\hline Sliding mass & 50 & 0.3 & 15 & 28 & - & 1900 \\
\hline Bedrock & $1.5 \times 104$ & 0.25 & 35 & 30 & - & 2500 \\
\hline stabilizing pile 1 (C20) & $2.0 \times 104$ & 0.2 & - & - & 13.4 & 2400 \\
\hline $\begin{array}{l}\text { stabilizing pile } 2 \\
\text { (C25) }\end{array}$ & $2.5 \times 104$ & 0.2 & - & - & 16.7 & 2400 \\
\hline $\begin{array}{l}\text { stabilizing pile } 3 \\
(\mathrm{C} 30)\end{array}$ & $3.0 \times 104$ & 0.2 & - & - & 20.1 & 2400 \\
\hline
\end{tabular}

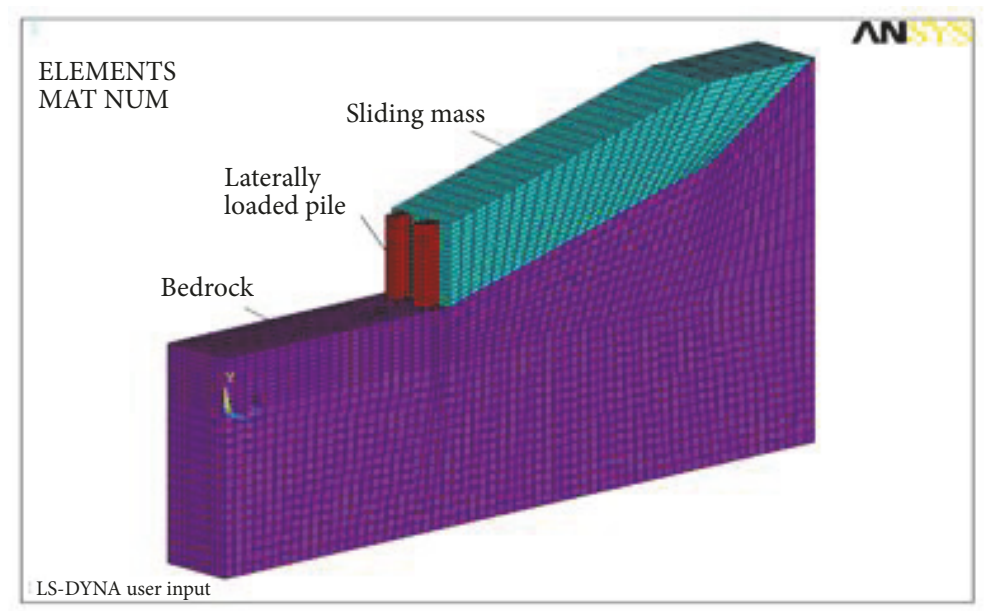

FIgURE 11: The calculated model.

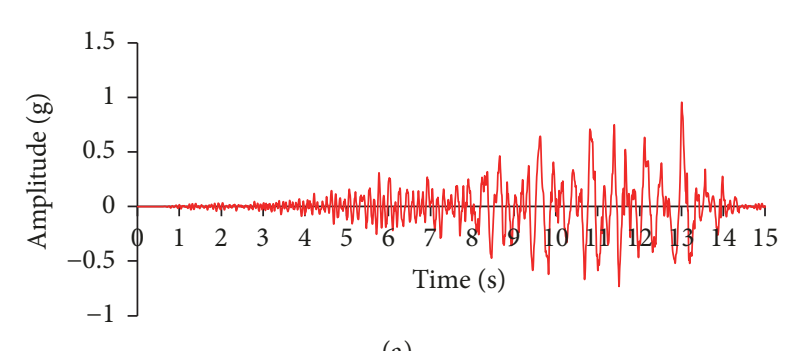

(a)

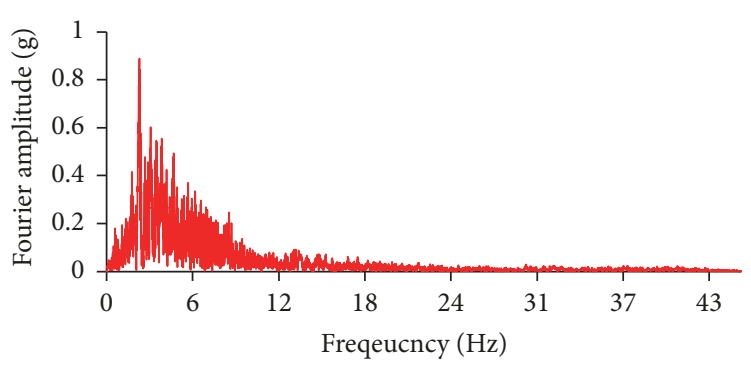

(b)

FIGURE 12: The acceleration and acceleration spectral curve after modification. (a) Acceleration time history curve; (b) Fourier spectral (EW) curve.

to stabilizing pile [21]. The acceleration curve and acceleration spectrum curve after manual processing are shown in Figure 12.

\section{Result Analysis}

In the simulation, the revised Wenchuan Wolong seismic wave was input along the stress direction of piles at the bottom of the model. In addition, PGA was selected $0.8 \mathrm{~g}$ to damage those piles. On the basis, the seismic response characteristics of displacement and equivalent stress during the process of damage were studied.
4.1. Time History Response Analysis of Stabilizing Piles. In the time history response analysis of stabilizing pile, the time and position of maximum displacement and maximum stress were considered. The displacement time history curve of the pile top and the equivalent stress time history curve of embedded section are shown in Figure 13.

Some conclusions can be seen from Figure 13. Firstly, as the ground motion time increases, the displacement of pile top shocks to increase. When the time reaches $12 \mathrm{~s}$, the displacement begin to increase slowly and tends to be stable gradually. Furthermore, the displacement after stability reaches $12.7 \mathrm{~cm}$. Secondly, the equivalent stress of stabilizing 


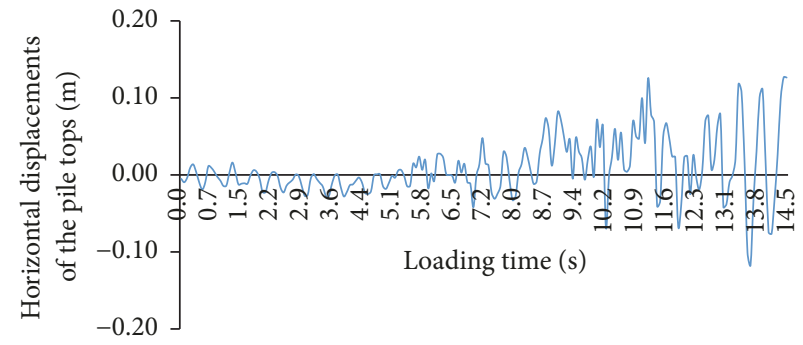

(a)

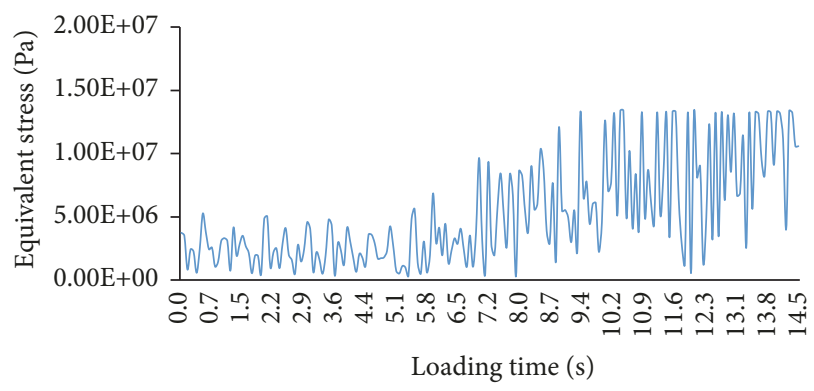

(b)

Figure 13: Displacement and equivalent stress time history curve of stabilizing piles. (a) The time history curve of displacement; (b) the time history curve of equivalent stress.

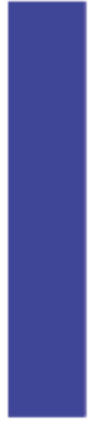

$\mathrm{T}=5.0 \mathrm{~s}$

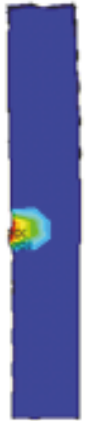

$\mathrm{T}=9.0 \mathrm{~s}$

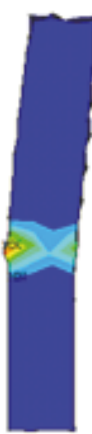

$\mathrm{T}=14.0 \mathrm{~s}$
Figure 14: The plastic strain cloud diagram of stabilizing pile at different vibration times.

pile also gradually increases with the increase of vibration time. When the time reaches about $10 \mathrm{~s}$, the plastic yielding occurs firstly so that the model enters plastic state. Since then, the equivalent stress comes up to the maximum and remains constant, whereas the plastic zone is not invariable until it runs through the whole section of stabilizing piles. Finally, according to the performance reaction of the stabilizing pile, the pile is in an elastic state at the beginning and then the plastic zone begins to occur with the increase of vibration time. In addition, as the time continues to increase, the plastic zone continuously spreads to the whole section, losing its working performance. The elastic-plastic states of the stabilizing pile with different times are shown in Figure 14.

4.2. Seismic Response Characteristics of Stabilizing Pile. According to the time history response analysis of stabilizing pile, the displacement and equivalent stress increase with the increase of the vibration time. Considering the seismic performance, the $13.63 \mathrm{~s}$ was selected as the most severe time of response and the worst time of seismic design, and then the overall displacement and equivalent stress response characteristics of stabilizing pile (that is to the meaning of "seismic response characteristics" in this paper) were studied [22]. Finally, the response curves of horizontal displacement and equivalent stress were obtained, as shown in Figure 15.

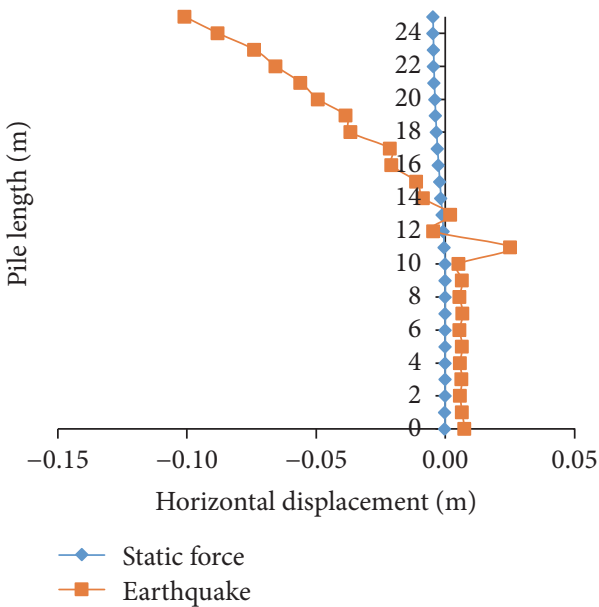

(a)

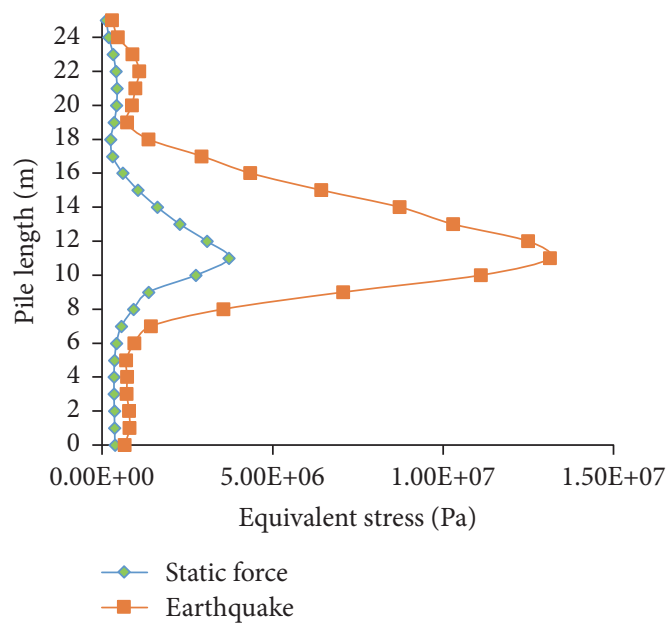

(b)

FIGURE 15: The dynamic response curve of stabilizing pile. (a) Horizontal displacement; (b) equivalent stress.

As is indicted from Figure 15, the displacement response under the seismic dynamic action is much larger than that of static state, where the displacement of the pile top is the 


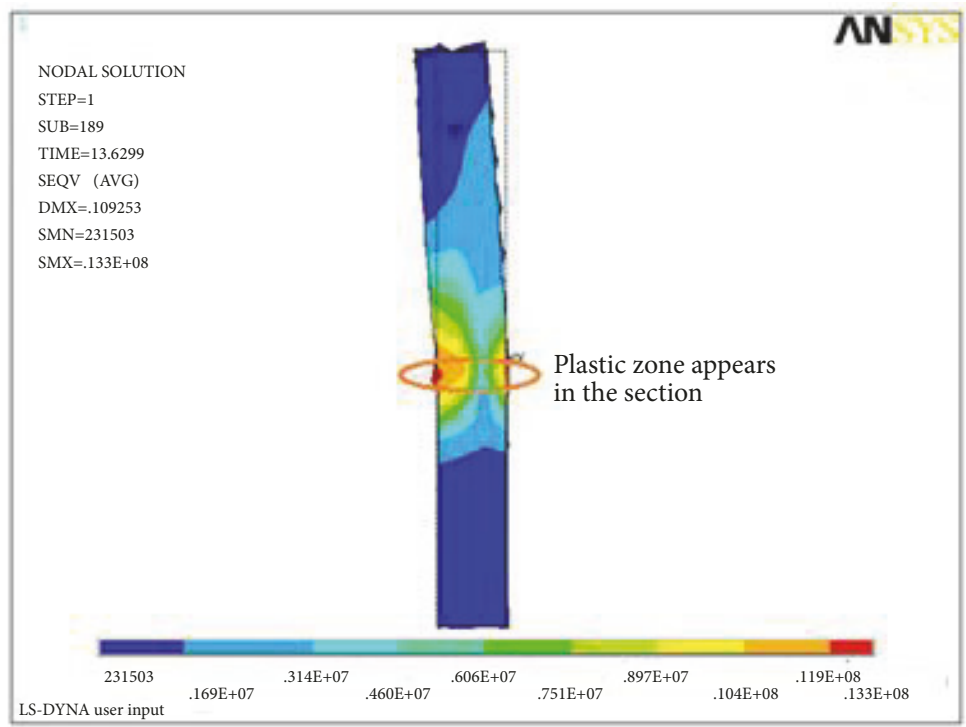

(a)

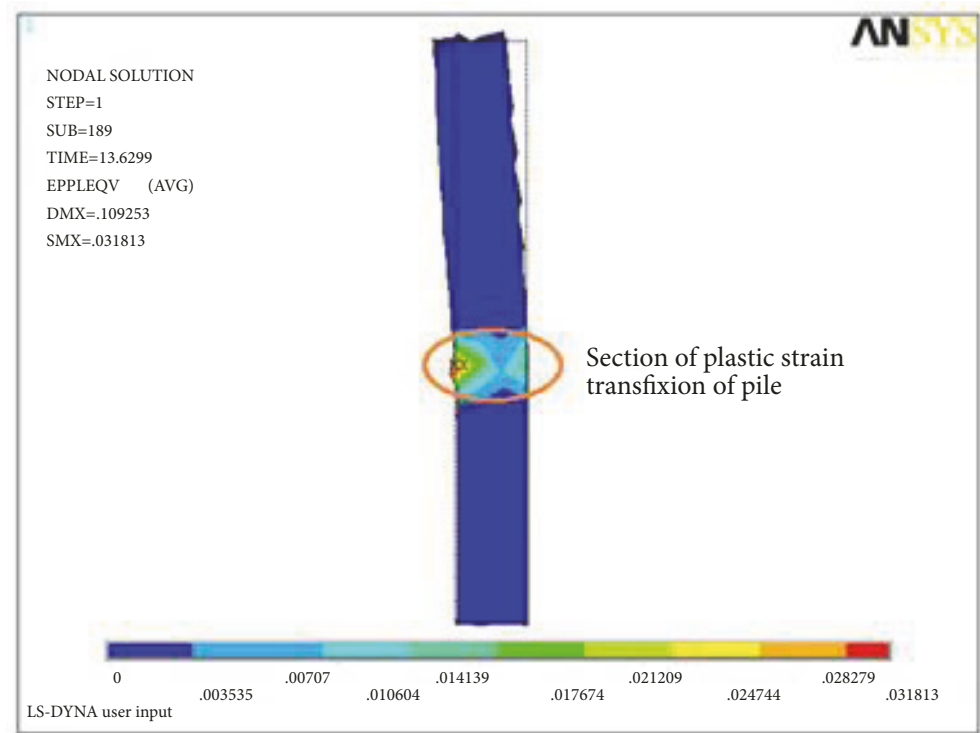

(b)

FIGURE 16: The plastic strain cloud diagram of stabilizing pile under the action of seismic force. (a) Equivalent stress; (b) plastic strain.

largest with the value of $10.1 \mathrm{~cm}$. As for equivalent stress, the static and seismic dynamic response curves have the same tendency; namely, equivalent stress reaches minimum at both ends of the pile, while it is the maximum near the embedded section. Similarly, the equivalent stress of the static state is far less than that of seismic action.

In addition, under the action of static state, the maximum of equivalent stress is $3.73 \mathrm{MPa}$ which has not reached the yield strength of the material, so it is still in elastic state. However, the maximum is $13.4 \mathrm{MPa}$ under the action of earthquake, which exceeds the yield strength, so it leads to the development of connected plastic zone. Finally, stabilizing pile starts to damage and loses its working performance gradually. The equivalent stress and plastic strain cloud diagram are shown in Figure 16.

\subsection{The Influence of Design Parameters on the Stabilizing Pile Performance}

4.3.1. Horizontal Displacement of Stabilizing Pile. The influence of material strength, section size, and PGA on the seismic response characteristics of stabilizing pile was also analyzed by controlling variable method, where the material strength included C20, C25, and C30 of reinforced concrete, the design dimensions included $B \times H=2 \times 2.5 \mathrm{~m}, 2 \times 3 \mathrm{~m}$, and $2 \times 3.5 \mathrm{~m}$, and the PGA included $0.2 \mathrm{~g}, 0.4 \mathrm{~g}$, and $0.8 \mathrm{~g}$. 


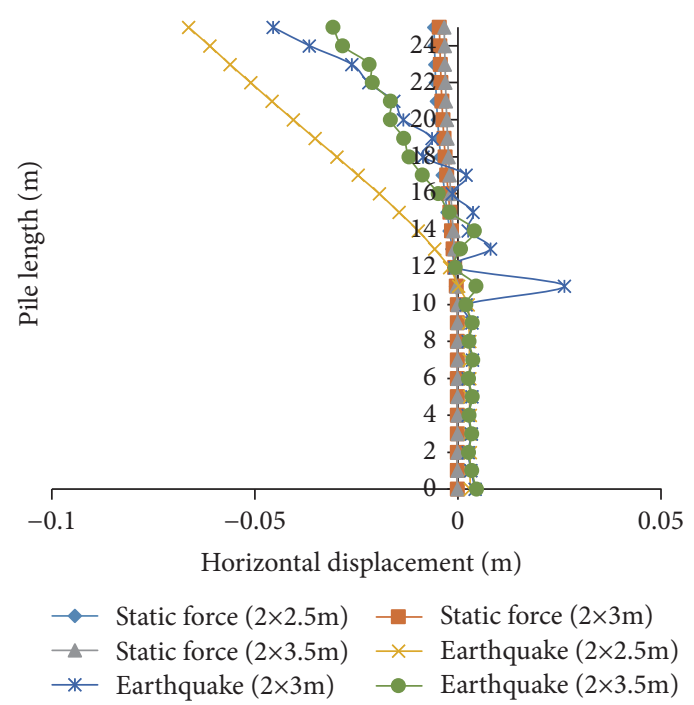

(a)

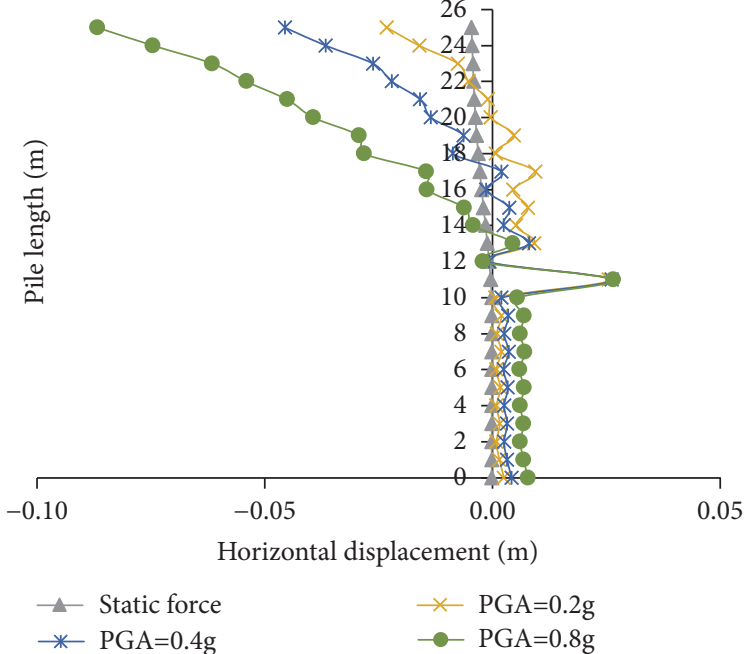

(b)

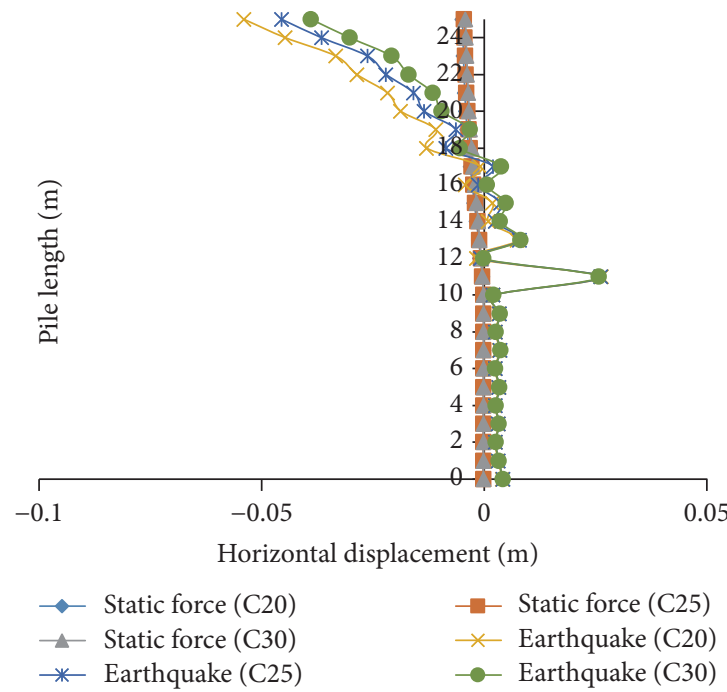

(c)

FIGURE 17: The displacement response curves of stabilizing pile in different working conditions. (a) Different section sizes; (b) different PGAs; (c) different material strengths.

The displacement response curves of stabilizing pile in different section sizes, PGAs, and material strengths are shown in Figure 17, and the corresponding plastic strain is shown in Figure 18.

It can be seen from Figures 17-18 that when the size of structure is larger, the displacement is smaller. Therefore, changing the sectional design size of stabilizing pile can reduce the seismic displacement effectively, leading to the decrease of plastic zone. In addition, the displacement increases with the increase of PGA. Under the action of earthquake, $0.2 \mathrm{~g}, 0.4 \mathrm{~g}$, and $0.8 \mathrm{~g}$ of PGA corresponds to $2.32 \mathrm{~cm}, 4.55 \mathrm{~cm}$, and $8.68 \mathrm{~cm}$ of displacement, respectively. However, the displacement is $1.02 \mathrm{~cm}$ with the static force. Additionally, the connected plastic zone exhibits plastic state in severe earthquake region so that the capacity of stabilizing pile will lose.
Similarly, when the material strength is larger, the displacement response is smaller, whereas the displacement difference of the stabilizing pile under static and seismic states is not obvious with the same structural material strength. Additionally, the plastic threshold of the material is improved by increasing the strength. Therefore, if the material strength changes, its plastic yield condition and bearing capacity can be enhanced availably.

4.3.2. Equivalent Stress of Stabilizing Pile. The equivalent stress response curves of stabilizing pile in different section sizes, PGAs, and material strengths are shown in Figure 19, and the corresponding plastic strain are shown in Figure 20.

As is indicated from Figures 19 and 20, equivalent stress of the stabilizing pile increases with the increase of PGA and decreases with the increase of section size and material 


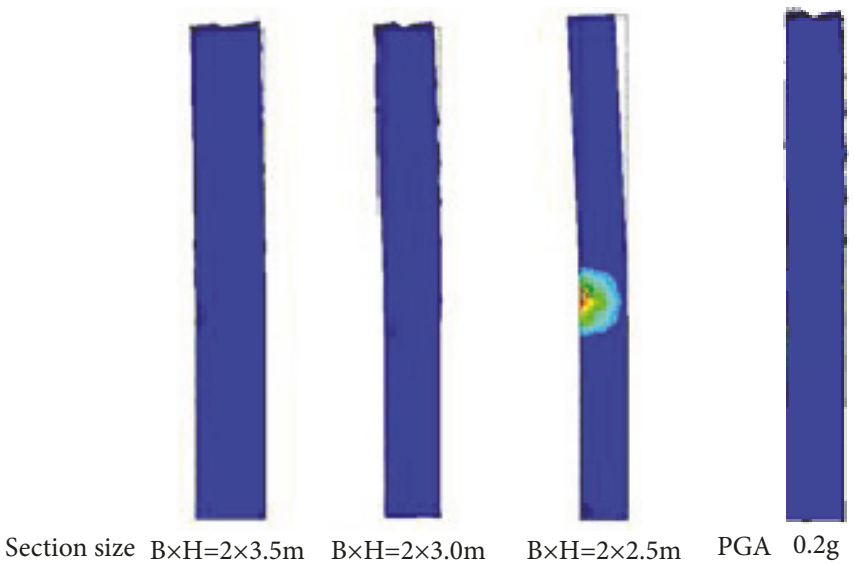

(a)

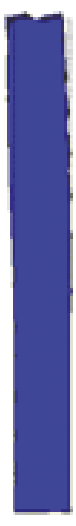

$0.4 \mathrm{~g}$

(b)

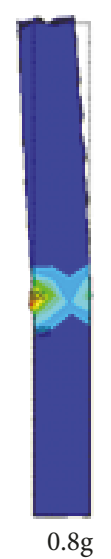

$0.8 \mathrm{~g}$

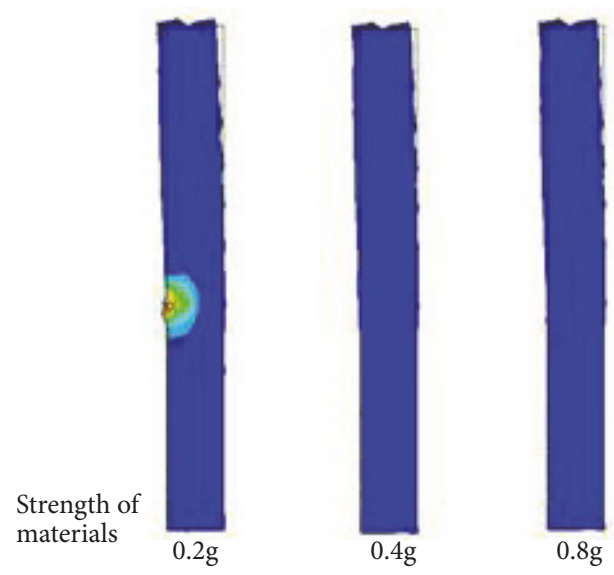

(c)

FIGURE 18: The plastic strain cloud diagram of stabilizing pile in different working conditions. (a) Different section sizes; (b) different PGAs; (c) different material strengths.

strength. In addition, the influence of section size is extremely obvious when the pile is affected by earthquake, while the influence of material stress is inconspicuous.

The variation of section size can efficiently reduce the equivalent stress of stabilizing pile. To be specific, under the action of earthquake, the maximum of equivalent stress near the embedded section is $16.7 \mathrm{MPa}, 13.6 \mathrm{MPa}$, and $11.3 \mathrm{MPa}$ when the section size is $B \times H=2 \times 2.5 \mathrm{~m}, 2 \times 3 \mathrm{~m}$, and $2 \times 3.5 \mathrm{~m}$, respectively. In the static force, the maximum of different design sizes all roughly equals $3.88 \mathrm{MPa}$. Hence, according to the analysis results of equivalent stress, the stabilizing pile with section size of $B \times H=2 \times 2.5 \mathrm{~m}$ reaches the yielding condition and starts to exhibit the plastic state; namely, the plastic zone is developing continuously. Nevertheless, the stabilizing piles with the remaining two sectional sizes are still in elastic state without yielding. Additionally, $0.2 \mathrm{~g}, 0.4 \mathrm{~g}$, and $0.8 \mathrm{~g}$ of PGA correspond to 6.52 $\mathrm{MPa}, 13.6 \mathrm{MPa}$, and $16.7 \mathrm{MPa}$ of the equivalent stress, respectively, while the value is $3.88 \mathrm{MPa}$ with different PGAs in the static force. Furthermore, plastic zone in stabilizing pile also develops when PGA equals $0.8 \mathrm{~g}$, whereas the stabilizing piles are still in elastic state when PGA is $0.2 \mathrm{~g}$ or $0.4 \mathrm{~g}$. When studying the influence of material strength, it is concluded that the equivalent stress with three materials (C20, C25, and $\mathrm{C} 30$ ) is $13.4 \mathrm{MPa}, 13.6 \mathrm{MPa}$, and $14.1 \mathrm{MPa}$, respectively, while it is about $3.07 \mathrm{MPa}$ in the static force. Accordingly, the pressure stress of the stabilizing pile with C20 exceeds its yield strength, leading to the development of plastic zone. Likewise, the stabilizing piles with the other working conditions are still in elastic state.

Additionally, the plastic threshold of the material is improved by increasing the strength. Therefore, if the material strength of stabilizing pile increases, its plastic yield condition and bearing capacity can be enhanced availably.

\section{Conclusions}

In order to analyze the seismic response characteristics of stabilizing pile based on elastic-plastic analysis, the constitutive relationship with isotropic hardening was deduced according to von Mises yield criterion, and then a numerical model was established by ANSYS. In view of this, the 


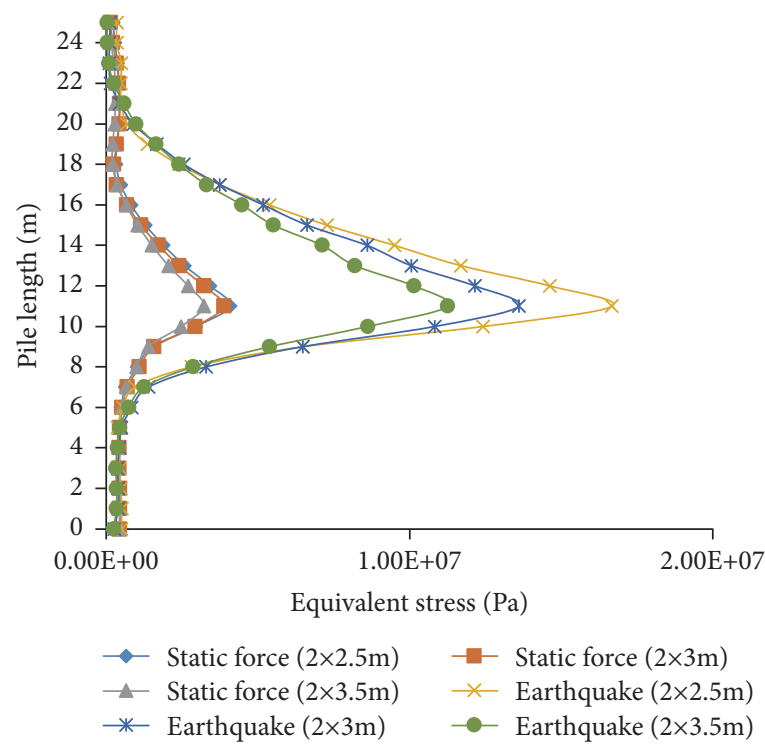

(a)

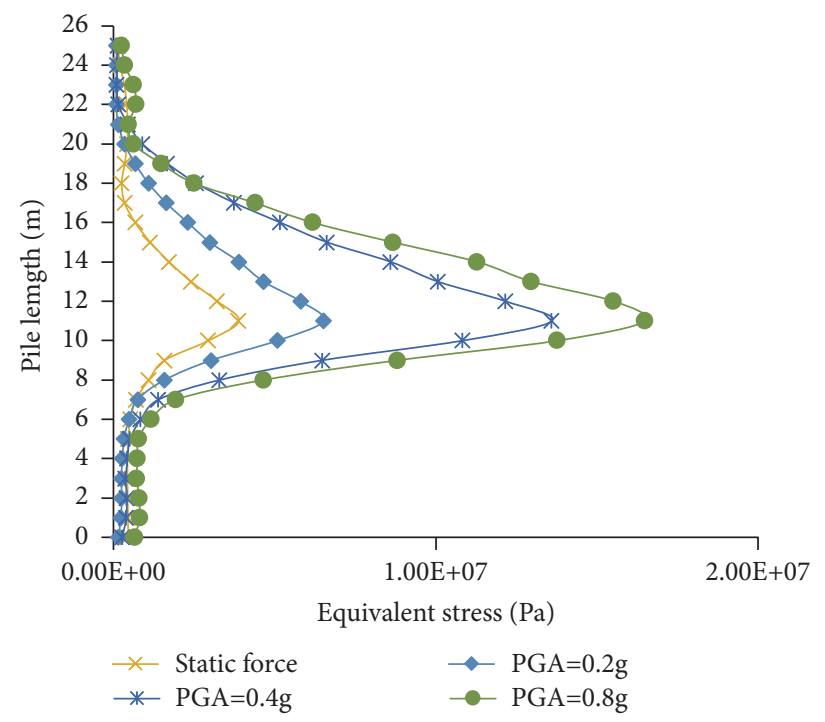

(b)

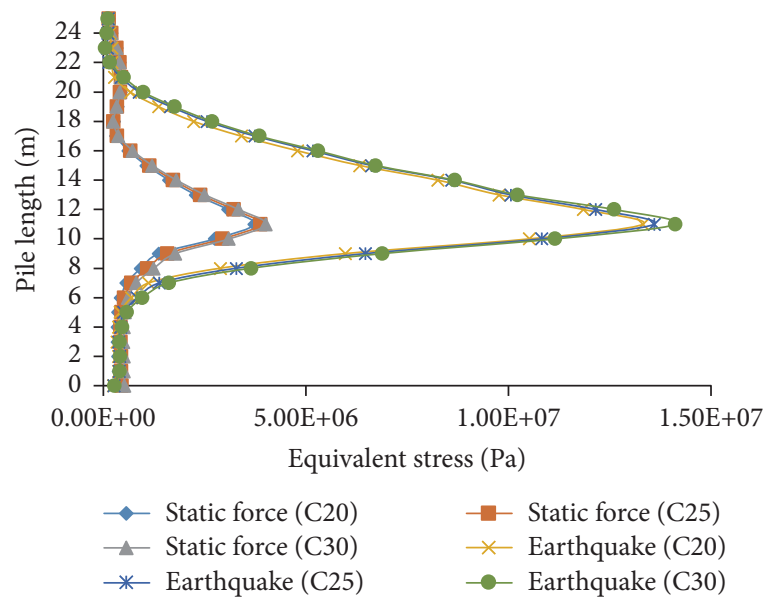

(c)

FIGURE 19: The equivalent stress curve of stabilizing pile in different working conditions. (a) Different section sizes; (b) different PGAs; (c) different material strengths.

seismic response characteristics and the influence of different design parameters on seismic performance were analyzed. The following conclusions can be obtained.

(1) The elastic-plastic constitutive relationship of isotropic hardening for stabilizing pile was obtained, and the elasticplastic fourth-order tensor $C_{i j k l}^{e p}$ was deduced, which can be used to calculate plastic strain under the action of earthquake. In addition, the plastic zone was deduced based on elastic limit state and plastic limit state.

(2) As for the piles of same size and same property, the ultimate stress based on elastic-plastic analysis is greater than that of static method. Therefore, the material of stabilizing pile working with elastic-plastic state will be decreased under the action of earthquake.

(3) Under the action of earthquake, stabilizing pile is in the elastic stage at the beginning. With the increase of ground motion time, the section starts to exhibit elasticplastic state and then the plastic zone expands gradually. Finally, the plastic zone runs through the whole section so that the stabilizing pile loses its working performance.

(4) Under the different design parameters, stabilizing pile shows different seismic response characteristics. Specifically, with the increase of section size, the displacement and equivalent stress decrease and so does the plastic zone. However, the increase of material strength improves the plastic threshold of pile. In addition, the stabilizing pile in high intensity seismic area may exhibit connected plastic zone so that losing its service capacity.

(5) According to the analysis of numerical simulation, it also confirms the feasibly that the elastic-plastic constitutive model deduced in this paper can study those isotropic hardening materials which meet von Mises yield criterion. 


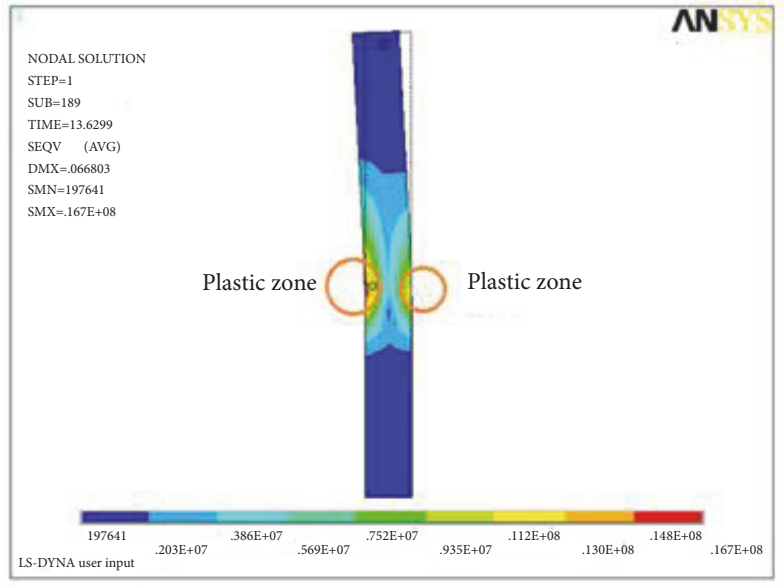

(a)

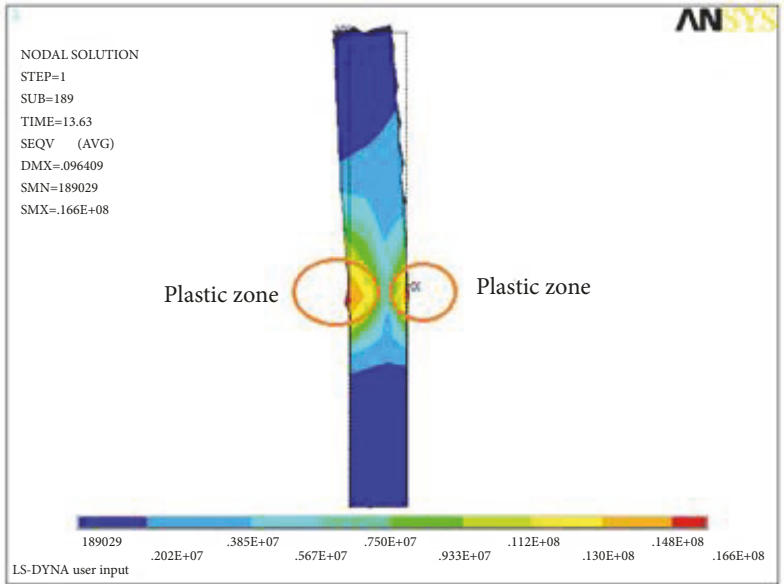

(b)

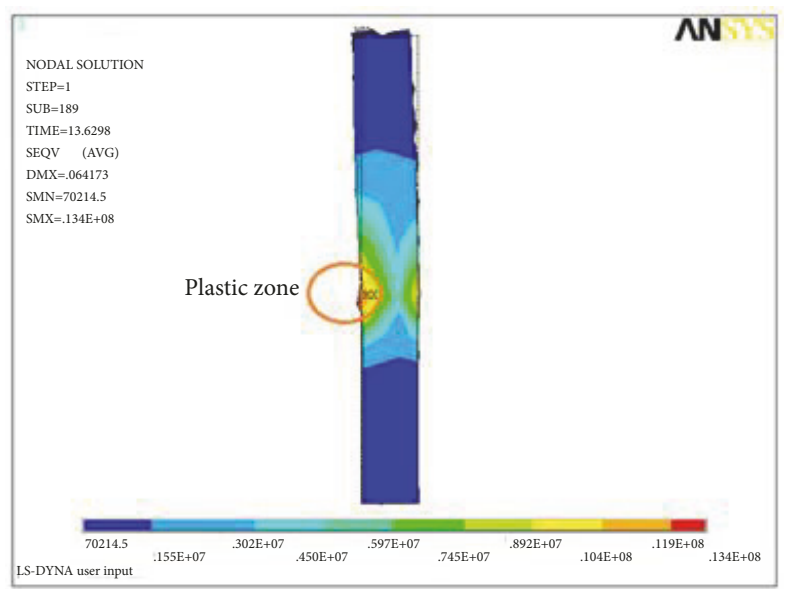

(c)

FIGURE 20: The equivalent stress cloud diagram of stabilizing pile in different working conditions. (a) Different section sizes; (b) different PGAs; (c) different material strengths.

\section{Data Availability}

The data used to support the findings of this study are included within the article.

\section{Conflicts of Interest}

The authors declare that they have no conflicts of interest.

\section{Acknowledgments}

This study is supported by the National Natural Science Foundation of China under Grant no. 41602332 and the Key Technology Research Project of Prevention and Control for Major Work Safety Accident under Grant no. 2014-3189.

\section{References}

[1] H. Sharafi and Y. Sojoudi, "Experimental and numerical study of pile-stabilized slopes under surface load conditions," International Journal of Civil Engineering, vol. 14, no. 4, pp. 221-232, 2016.
[2] M. R. Kahyaoğlu, G. İmançlı, G. Özden, and A. Ş. Kayalar, "Numerical simulations of landslide-stabilizing piles: a remediation project in Söke, Turkey," Environmental Earth Sciences, vol. 76, no. 19, 2017.

[3] M. M. Yamin, M. F. Attom, and R. Y. Liang, "Solutions for Soil-Pile-Soil Forces in Pile Stabilized Slopes," Geotechnical and Geological Engineering, vol. 35, no. 4, pp. 1859-1869, 2017.

[4] H. L. Qu, R. Li, J. J. Zhang, H. Hu, and D. Zhang, "A novel approach for seismic design of anchored sheet pile wall," Tehnički vjesnik, vol. 23, no. 2, pp. 455-463, 2016.

[5] E. A. Ellis, I. K. Durrani, and D. J. Reddish, "Numerical modelling of discrete pile rows for slope stability and generic guidance for design," Géotechnique, vol. 60, no. 3, pp. 185-195, 2010.

[6] R. Kourkoulis, F. Gelagoti, I. Anastasopoulos, and G. Gazetas, "Slope stabilizing piles and pile-groups: Parametric study and design insights," Journal of Geotechnical and Geoenvironmental Engineering, vol. 137, no. 7, pp. 663-677, 2011.

[7] H. L. Qu, H. Luo, L. Liu, and Y. Liu, "Analysis of Dynamic Coupling Characteristics of the Slope Reinforced by Sheet Pile Wall," Shock and Vibration, vol. 2017, 10 pages, 2017. 
[8] Z. Sun, L. Kong, and A. Guo, "Centrifuge modeling tests on seismic response of lower bedrock deposit slopes before and after reinforced with stabilizing piles," Yanshilixue Yu Gongcheng Xuebao/Chinese Journal of Rock Mechanics and Engineering, vol. 36, no. 6, pp. 1413-1423, 2017.

[9] M. Bakri, Y. Y. Xia, and H. B. Wang, "Numerical analysis of stabilization of slopes overlying bedrock using piles and effect of socketed length of pile on stability," Applied Mechanics and Materials, vol. 580-583, pp. 424-431, 2014.

[10] T. Chen, K. Guo, M. Yang, S. Chen, and H. Chen, "Calculation method of anti-slide piles spacing considering the soil arching effect," in Proceedings of the 2016 International Conference on Mechanics and Architectural Design, pp. 461-466, Suzhou, China, 2017.

[11] S. Xiao, "A simplified approach for stability analysis of slopes reinforced with one row of embedded stabilizing piles," Bulletin of Engineering Geology and the Environment, vol. 76, no. 4, pp. 1371-1382, 2017.

[12] Q.-Y. Fan, M.-Q. Wang, and S.-C. Xu, "Calculation on the internal force of deeply buried anti-slide pile by using finite difference method based on the m-k type method," Applied Mechanics and Materials, vol. 130-134, pp. 128-134, 2012.

[13] L. Luan, Y. Liu, and Y. Li, "Numerical Simulation for the SoilPile-Structure Interaction under Seismic Loading," Mathematical Problems in Engineering, vol. 2015, Article ID 959581, 7 pages, 2015.

[14] G. Khorami Fard and I. Rasoolan, "Soil-Pile Interaction Analysis Using Multi-laminate Elasto-Plastic Modelling," Geotechnical and Geological Engineering, vol. 35, no. 4, pp. 1665-1683, 2017.

[15] H. Qu, H. Hu, R. Li, and Y. Ma, "Influence of concrete strength on performance of stabilizing pile," Electronic Journal of Geotechnical Engineering, vol. 20, no. 4, pp. 1541-1550, 2015.

[16] H. Qu, R. Li, H. Hu, H. Jia, and J. Zhang, "An approach of seismic design for sheet pile retaining wall based on capacity spectrum method," Geomechanics and Engineering, vol. 11, no. 2, pp. 309323, 2016.

[17] C. Giarlelis and G. Mylonakis, "Interpretation of dynamic retaining wall model tests in light of elastic and plastic solutions," Soil Dynamics and Earthquake Engineering, vol. 31, no. 1, pp. 16-24, 2011.

[18] C. Rainieri, G. Fabbrocino, and F. S. De Magistris, "An integrated seismic monitoring system for a full-scale embedded retaining wall," Geotechnical Testing Journal, vol. 36, no. 1, pp. $1-14,2013$.

[19] "B50011-2006 Code for seismic design of railway engineering," 2006. (in Chinese).

[20] “TGB02-2013 Specification of seismic design for highway engineering," 2013. (in Chinese).

[21] S. P. G. Madabhushi and X. Zeng, "Simulating seismic response of cantilever retaining walls," Journal of Geotechnical and Geoenvironmental Engineering, vol. 133, no. 5, pp. 539-549, 2007.

[22] R. Conti, G. M. B. Viggiani, and F. Burali D’Arezzo, "Some remarks on the seismic behaviour of embedded cantilevered retaining walls," Géotechnique, vol. 64, no. 1, pp. 40-50, 2014. 


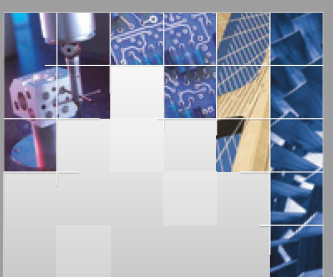

\section{Enfincering}
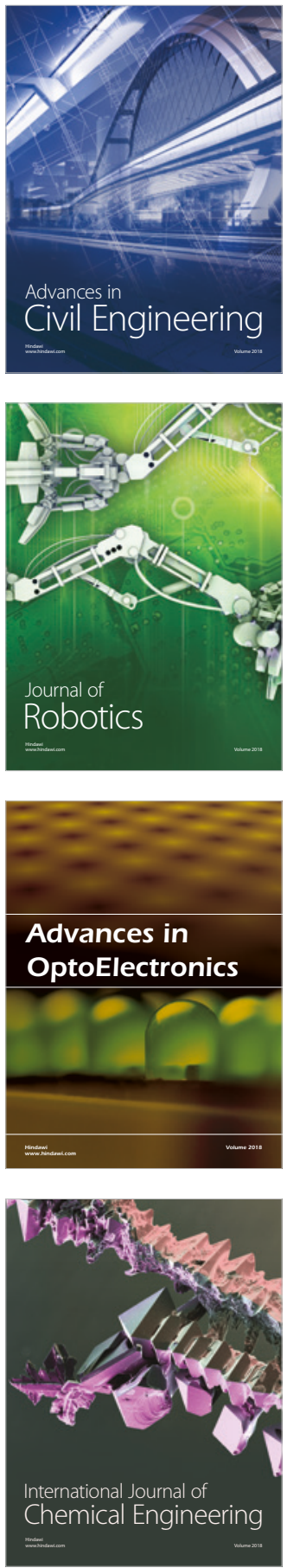

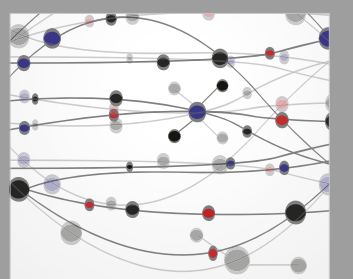

\section{Rotating \\ Machinery}

The Scientific World Journal

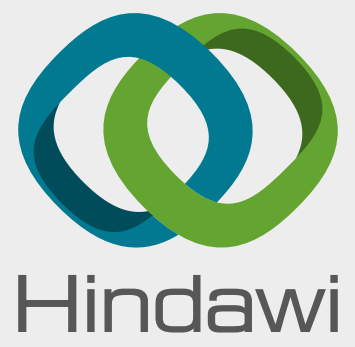

Submit your manuscripts at

www.hindawi.com
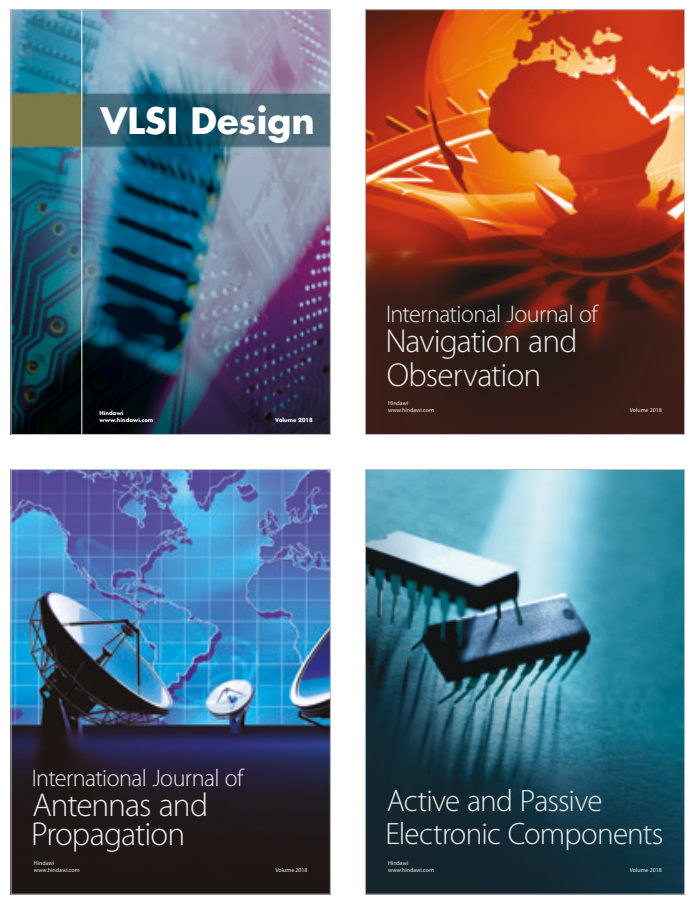
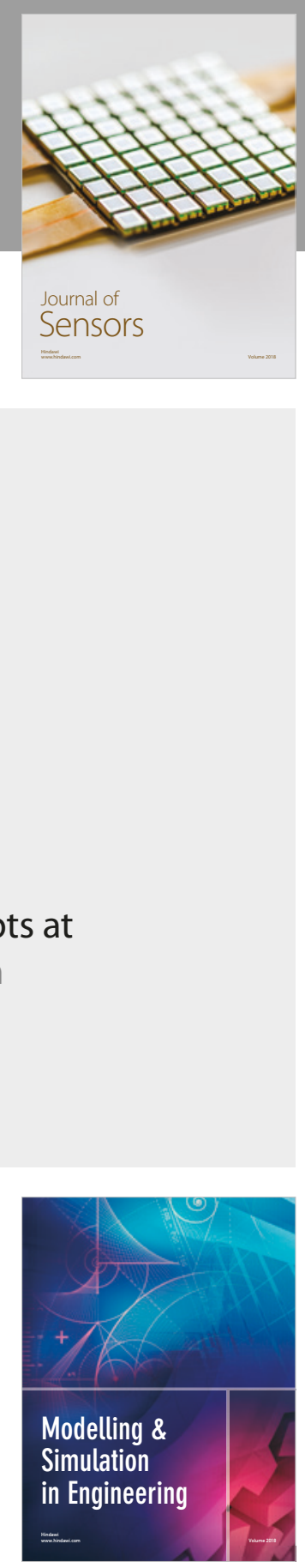

\section{Advances \\ Multimedia}
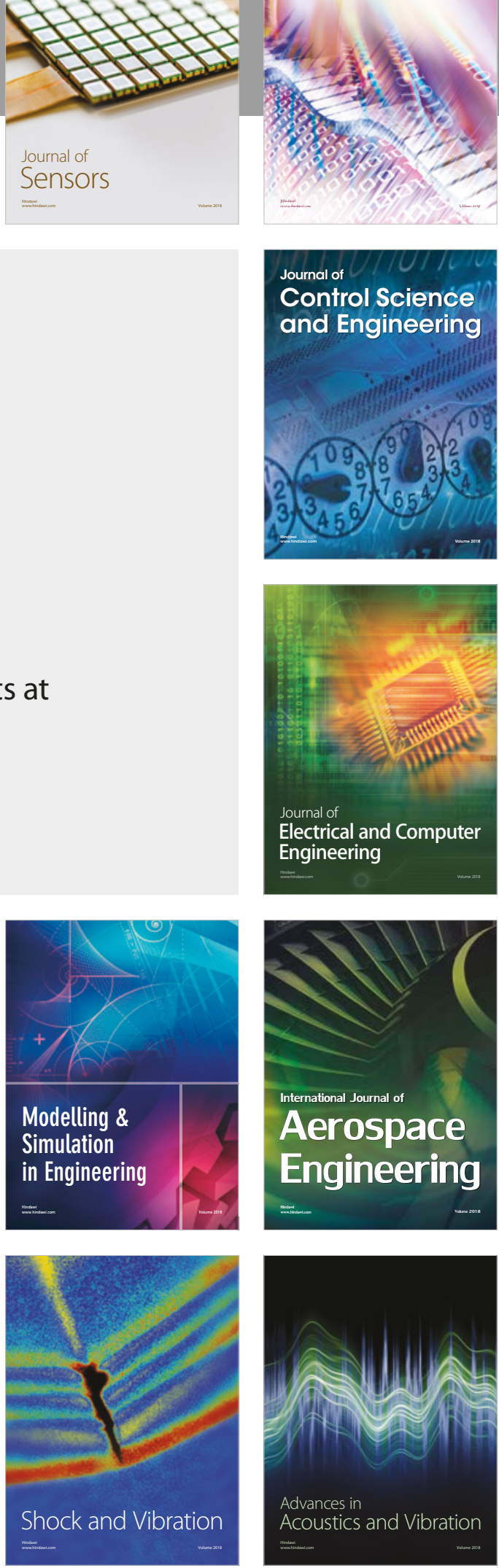